\title{
THE ROLE OF INFORMATION AND COMMUNICATION TECHNOLOGY IN GUEST SATISFACTION ANALYSIS IN HOSPITALITY
}

\author{
Slobodan Čerović, \\ Miroslav Knežević, \\ Dušan Borovčanin
}

Singidunum University, 32 Danijelova Street, Belgrade, Serbia
Correspondence:

Dušan Borovčanin

e-mail:

dborovcanin@singidunum.ac.rs

\begin{abstract}
:
The aim of this paper is to demonstrate the extent to which information and communication technologies (ICT) are used in the analysis of hotel guest satisfaction in Serbia. Moreover, this paper examines modern solutions in the field of ICT and benefits that they are providing for hotel managers. We started by analyzing theoretical background which considers the influence of IT on hospitality, following the research that was conducted on the level of ICT implementation in the analysis of guest satisfaction in hotels in Serbia. In addition, we wanted to show that the usage of ICT in this domain is much more rational regarding some major economic principles such as efficiency and profitability.
\end{abstract}

Key words:

ICT, guest satisfaction, hotel, on-line reputation.

\section{INTRODUCTION}

Globalization and development of the tourism industry has increased and accelerated greatly the need for information, without which doing business in tourism and hospitality could be hardly imaginable. Moreover, with the development of modern ICT the need for their application in business becomes the key for the competitiveness of hotel industry. [1] ICT development has created numerous changes in promotion and sales of hotel services. Management, revenue management, capacity optimization, establishing and developing of relationships with customers and other activities are acquiring a new look influenced by modern technologies. There are four key elements that affect and shape modern business. [2]

- Digitalization and relationships

- Internet expansion

- Contemporary intermediation methods

- Adaptation to the needs and expectations of consumers.

Since consumers are the starting and the ending point of all business processes in a hotel, their satisfaction is one of the most important elements that has a considerable impact on the results achieved in the hotel 
business. In addition, technological progress and tourism have been going hand in hand for years. [3] The internet and communication technologies are creating new opportunities and resources to improve the competitiveness and profitability of tourist destinations and enterprises in the future. [4] [5] From a business perspective, contemporary trends in the field of e-tourism are focused on consumers, as well as the advantages offered by creation of network and partnerships with other tourism enterprises (companies) that provide complementary services. [5]. Based on the analysis of trends and opportunities arising from the development of modern information technology, the habits and consumer expectations have changed profoundly. Tourists are more demanding and they require differentiated and personalized services. In accordance with these, tourism businesses should collect information about tourists at every stage of the tourist experience (before, during and after travel). This should be in particular the information created by the tourists themselves on the Internet, which should be used to better understand the needs and attitudes of users, and to offer more personalized services and, in general, to develop user-oriented promotional strategies. [6]

Modern ICT tools can help tourism enterprises to increase profitability, but also to significantly improve the quality of their services. First of all, ICT tools provide an opportunity to create and develop direct relations with customers, which contributes to sales and reduces the amount of fees payable to various intermediaries and other distribution channels. Furthermore, enabling web reputation management provides an opportunity to improve hotel reputation and identity. In addition, the internet and communication technologies are indispensable support within the following activities: [7]

- Market segmentation

- Price optimization

- Demand forecasting

- Supplies allocation

- Sales etc.

When it comes to the benefits arising from the creation of the partnership, it is known that the tourism product is actually a set of services that is diverse in nature, and that the evaluation of the quality basically depends on the user's overall experience which is a result of the mix of services offered by different companies. [8]

Having in mind everything mentioned so far, the research in this paper was conducted in order to determine the percentage of software usage for the analysis of guest satisfaction in hotels in Serbia.

\section{GUEST SATISFACTION AND MODERN INFORMATION TECHNOLOGIES}

Numerous studies have dealt with the issue of customer satisfaction. In the second half of the twentieth century, Peterson and Wilson (1992) estimated that 15,000 studies were done on consumer satisfaction or dissatisfaction. [9] Other reserches showed that operational productivity and customer satisfaction are the important performance indicators in the hotel industry.[10] A large number of definitions associate user satisfaction with product quality, or the quality of delivered services. Therefore, the quality of the service provided in the hotel industry has to be viewed from the perspective of the final user,which is in this case hotel guest. Bearing in mind that the consumer satisfaction represents, in fact, only the perception of the value delivered, hotel managers have to find out what is actually a value for the consumer [2] Certainly, this is much more important given that the difference between consumer expectations and perceived performance of products and services, represents satisfaction or dissatisfaction of guests.

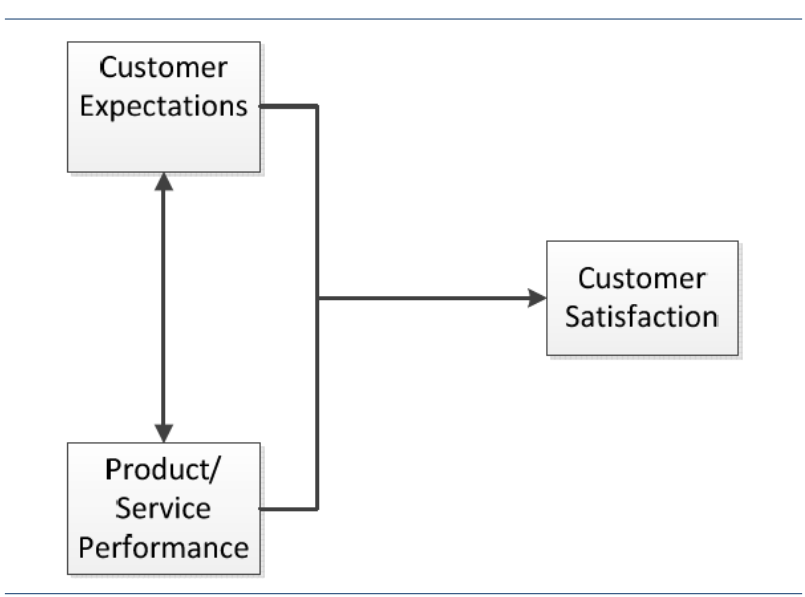

Figure 1. Customer satisfaction model ${ }^{1}$

Satisfaction and dissatisfaction analysis is one of the important preconditions for the successful hotel business, bearing in mind the above-mentioned importance of satisfaction. However, in satisfaction analysis, modern information technologies are irreplaceable compared to traditional methods in terms of basic economic principles such as efficiency, productivity and profitability. As regards guest satisfaction in hospitality and their relation

1 Adapted from: "An Integrated Model for the Effects of Perceived Product, Perceived Service Quality, and Perceived Price Fairness on Consumer Satisfaction and Loyalty" 2001 Ti-Bei L. Journal of Consumer Satisfaction, Dissatisfaction and Complaining Behaviour 
to information and communication technologies, we primarily refer to marks that guests leave on the Internet distribution systems (IDS) and the comments as well. In this paper, we will also present a specific method of semantic processing of words in situations where hotel was mentioned in any context on the Internet.

Various studies indicate the importance of the comments and ratings of other guests when choosing a hotel, while individuals go a step further and directly link hotel revenues with a score at IDS. There are several factors to confirm this. First, the percentage of consumers consulting reviews at TripAdvisor prior to booking a hotel room has steadily increased over time, as has the number of reviews they are reading prior to making their hotel choice. [11] Second, in general, over 70\% of respondents usually start researching on-line before they decide how and where they want to travel. [12] In addition, various studies demonstrated that if a hotel increases its review scores by 1 point on a 5-point scale (e.g., from 3.3 to 4.3), the hotel can increase price by 11.2 percent and still maintain the same occupancy or market share. [11] Furthermore, the occurrence of recent positive reviews can over-ride or moderate the effect of a set of negative reviews, in respect of booking intentions. [13] All this is the reason why we consider the analysis of guest satisfaction crucial in modern business, while in the continuation of work we focused on ICT solutions that are created for more efficient and better approach to this issue and their implementation in hotels in Serbia. All of the above mentioned clearly demonstrates why we consider the analysis of guest satisfaction crucial in modern hotel management. Therefore, research below was focused on ICT solutions that were created for more efficient and better approach to this subject and their implementation in hotels in Serbia.

\section{THE USAGE OF ICT IN GUEST SATISFACTION ANALYSIS IN HOTELS IN SERBIA}

Over the past 5 years, the hotel industry in Serbia has been significantly growing. The overall structure is still dominated by small and medium-sized enterprises (SME's) despite a considerable share of international corporate hotel chains in Belgrade.[14] The aim of the research was to determine the level of usage of software in guests satisfaction analysis in hotels in Serbia. A totalsample comprised 31 hotel in Serbia. When designing this sample, special emphasis was placed on excluding corporate hotel chains that use corporate questionnaires for guest satisfaction analysis, like heartbeat from IHG. In the total sample, mountain hotels represented $19.35 \%$, Spa hotels $6 \%$, while the rest $74.65 \%$ were city hotels. This structure is primarily the consequence of the fact that the vast number of hotels in Serbia are located in urban centers.

The results obtained from the research show that only $3 \%$ of hotels use software to analyze guest satisfaction, ie. only 1 out of 31 hotels surveyed. [figure 3] After the quantitative data, we decided to do an interview with the manager of hotel that use software to analyze customer satisfaction and requested that he presents the main advantages of software usage.

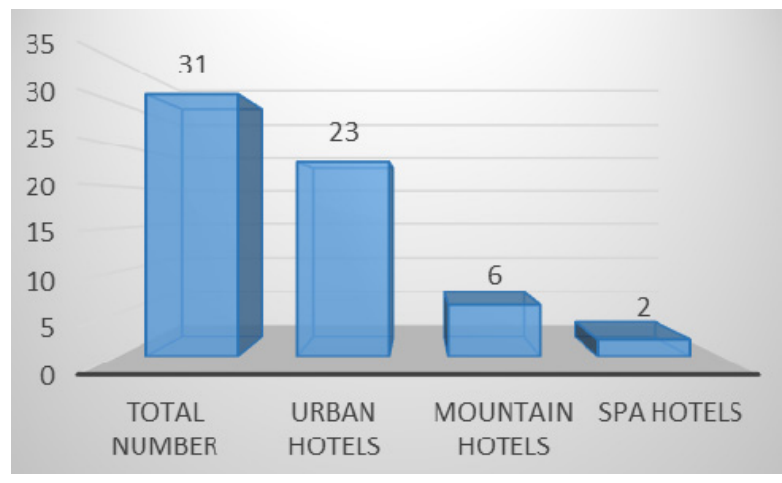

Figure 2. Sample statistics

One of the major advantages is analysis of online reviews and online presence in real time in one place, which is confirmed by comments collected from an interview that say "insight and analysis of all comments and marks on IDS portals are the biggest advantage for us, and at the same time it serves us as an insight into the quality of service we provide, everything in real time".

Thus, despite the fact that these tools allow managers to manage guest comments and marks in real time on all IDS's, they automatically serve as well, as an imputs for taking corrective action if they notice a negative trend in specific business segments.

The results that we have also come to by interview are as stated "greater ability to continue building relationships with guests after their stay and thus affect their loyalty. We realized that a higher percentage of guests prefer to expresses their dissatisfaction when not directly contacted by the staff" 
However, when we sought to determine the disadvantages or deficiencies which could be defined, only the two could be singled out:

- Automatically sent questionnaries to guests after a night audit (regular guest paradox)

- Some things that are not directly related to the quality of service can affect the overall assessment, which automatically becomes publicly available

The first disadvantage mentioned is due to the fact that the system automatically sends a questionnaire to the guests who spent the night in the hotel. This can become burdensome for those who have a very large number of overnight stays in a hotel regulary.

Also, the implementation of such solution requires certain level of readiness for transparency and the desire to be open in communication with former and prospective guests. This means that guests are given the opportunity and insight into all the good and bad comments that former guests stated during their stay. Some sort of comments like "unfriendly taxi driver, bad weather, etc." can spoil guests experience. Although this assessment is not directly linked to the quality of the service provided, those reviews automatically go public, and can influence future guests that are reading those reviews.

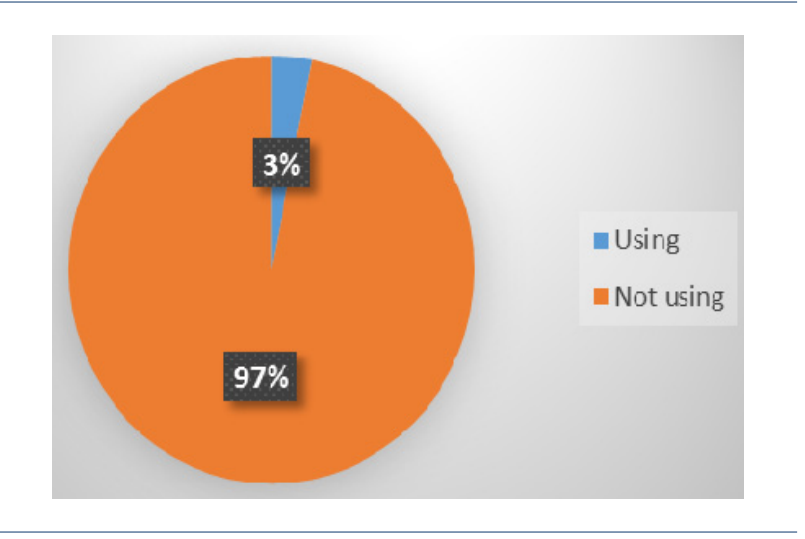

Figure 3. Sample statistics

However, after interviewing the management, we have found that the benefits and advantages of using this software go far beyond that, as confirmed by the following statement:

"The fact that we can track, and we can make operational plans based on the comments means a lot to us, as well as the ability to track and monitor our competition."

After all that we have examined, we decided to test one of the solutions in the field of ICT in this area. The test results are presented below.

\section{ICT TOOLS FOR HOTEL GUEST SATISFACTION ANALYSIS}

There has been a large number of softwares that were created so far, which enables modern managers to analyze the level of guest satisfaction in a more efficient way. Some of the most commonly used are: ReviewPRO, Customer Alliance, Revinate etc.. Every software is different, even though it basically provides almost the same or similar functionality for the hotel managers. The main benefits are: simple, efficient and reliable on-line reputation management of the hotel. In addition, such analysis reduces the pressure from hoteliers, says Susan Ganeshan, chief marketing and product officer at newBrandAnalytics. ${ }^{2}$

Below we will explain how these software can help in the analysis of guest satisfaction or dissatisfaction with hotel services.

Figure 4 (look in the appendix) shows the initial view or a dashboard of the "Customer Alliance", which gives manager an overview of all IDS channels on which the hotel is advertised. Furthermore, the graphical display on the right side indicates the share of each IDS according to the number of reviews. In this way, the hotel manager can simultaneously obtain information on which IDS guests are the most active, i.e. on which IDS they leave the largest number of reviews and comments. Managers can, of course, edit the look of their dashboard. However, the distribution of a review-by IDS's actually represents one of the basic data, which is why we decided to present it in this dashboard. Managers are given the freedom to choose information on the dashboard from the following filters: specific IDS's, average rating by IDS, descending and ascending trends IDS's and by the number of total reviews on IDS.

Figure 3 shows some of the basic statistical data such as:

- Count of total reviews

- Average score on IDS

- Trend in a given period of time

- The percentage of guests who leave their comments (comment rate)

It should be noted that the manager has the option of creating an independent statistical display according to the two important categories:

- Time period

- Individual or group

2 Digital Marketing, March 2013, interview on topic "Reputation Management, Social Media gets Visual" 
However, in addition, managers have at their disposal a detailed segmentation according to the comments:

- Demographic characteristics (age)

- Behavioral characteristics (new user, re-users etc.).

- Aspects of quality (Cleanliness, Staff friendliness, comfort of rooms, location)

The next essential component that ICT allows is semantic processing of words from reviews, but not only from reviews but from public portals, public profiles on social medias well. This important component enables managers to define the context in which guests usually mention the hotel, , as well as the keywords used in a positive or negative context.

Figure 5, on the left side, shows the table which sorts the keywords that guests most commonly use in their reviews. Software sorts them into two groups: 1) positive and 2) negative.

The groups are marked with plus and minus so that the manager can clearly see what are the keywords that lead to satisfaction or dissatisfaction.

With graphical display, on the other side of the figure, manager can perceive that currently prevails a positive or a negative trend. In the same figure, we can see that the words "Hotel" and "Breakfast " are the two most commonly mentioned words and that there is a positive context which prevails when they are mentioned. By simply clicking on any word, the software allows hoteliers to accurately see which user, at what time, on which IDS in particular, mentioned hotel in a positive or negative way. It allows hotel managers to thank for a comment or a suggestion to the guest directly.

In addition, the next component that we considered as important is the analysis of the competition. This kind of ICT solution allows tracking of main competitors, and gives an insights into trends of their comments and marks on IDS's.

Figure 7 shows the trend observed in 5 competing hotels and changes in their score and comments on IDS over time. In this way, the hotel manager can get a realtime benchmark analysis of its property and the competitors on IDSs. Thus, a hotel manager can determine strong and weak points following its own rating and the rating of its main competitors, and set up a simple SWOT analysis based on guest satisfaction.

\section{CONCLUSION}

Numerous studies have shown us how the Internet and ICT have changed the tourism industry. In 2014, the Internet became the most commonly used method of holiday organization. [15] One of the reasons why passengers have more confidence in the internet is the development of CGM (Consumer Generated Media). A strong part of CGM are guest reviews.

Although there are still authors who do not link the use of information and communication technologies and guest satisfaction, [16] the prevailing point of view is that ICT significantly affect the performance of the hotel, which clearly leads to a higher quality of services provided, and clearly to the satisfaction of guests and finally a large number of reservations and loyal guests. After all, a large number of managers in the leading hotels have supported this statement in their interviews, such as Sven Appelt, Best Western Plus Director who says that "this significantly affects our internet bookings"

Based on the results of the survey, it could be observed that the percentage of hotels in Serbia using ICT solutions in the satisfaction analysis remains extremely low. Even though a lot of managers around the world talks about the benefits from using this software, it remains to determine the reasons for such a low implementation of the software in Serbia, which will certainly be the subject of our further research, as well as the use of other ICT solutions in the field of hospitality.

In additions to the results of the research conducted herein, the authors have presented the benefits of using the software that helps hotel mangers to analyze the level of guest satisfaction. It is shown how it could be easy to monitor all marks and reviews as well as the semantic analysis of all public posts that mention a particular hotel, and finally the benchmark with competitive facilities and their ratings.

It also allows the hotel management to promptly and with high security determine specific weak points and make the right decision in order to live up to its customers' expectations.

\section{REFERENCES}

[1] Buhalis, D., \& Molinaroli, E. (2003). Entrepreneurial networks in the Italian eTourism. Information Technology and Tourism, 5(3) ,pp 175-184.

[2] Živković, R. (2014). Ponašanje potrošača. Beograd: Univerzitet Singidunum. 
[3] Sheldon, P. (1997). Tourism information technologies. Oxford: CAB.

[4] Buhalis, D. (2003). ETourism: information technology for strategic tourism management. Harlow,: Financial Times Prentice Hall.

[5] Buhalis, D., \& O'Connor, P. (2005). Information communication technology revolutionizing tourism. Tour Recreat Res, 7-16.

[6] Minazzi, R. (2015). Social Media Marketing in Tourism and Hospitality. Springer.

[7] Mauri, A. (2012). Hotel revenue management, Principles and practices. Milan: Pearson..

[8] Grönroos, C. (2000). Service management and marketing: a customer relationship management approach. Chichester: Wile.

[9] Peterson R. Wilson W. "Measuring customer satisfaction: Fact and artifact",Journal of the Academy of Marketing Science,1992,vol.20,pp 61-71

[10] Johnston, R. and Jones, P. (2004), "Service productivity: towards understanding the relationship between operational and customer productivity",
International Journal of Productivity and Performance Measurement, Vol. 53 No. 3, pp. 201-13.

[11] Anderson C. 'The Impact of Social Media on Lodging Performance "Cornell Hospitality Report, 2012, pp. 5-11.

[12] Ipsos MediaCT/Google Travel Study, 'Traveler's Road to Decision: Affluent Insights" May-June 2013.

[13] Sparks B., Browning V.’The impact of online reviews on hotel booking intentions and perception of trust" Tourism Management, 2013, pp.1310-1323

[14] http://mtt.gov.rs/sektori/sektor-za-turizam/korisne-informacije-turisticki-promet-srbija-kategorizacija/

[15] European Commission, Flash Eurobarometer 414 "Preferences of Europeans towards tourism" March 2015

[16] Sirawit S., Nazrul I., Do Ba Khang 'Does ICT adoption enhance hotel performance?" Journal of Hospitality and Tourism Technology 2(1) · march 2011, pp 34-39

\section{APENDIX}

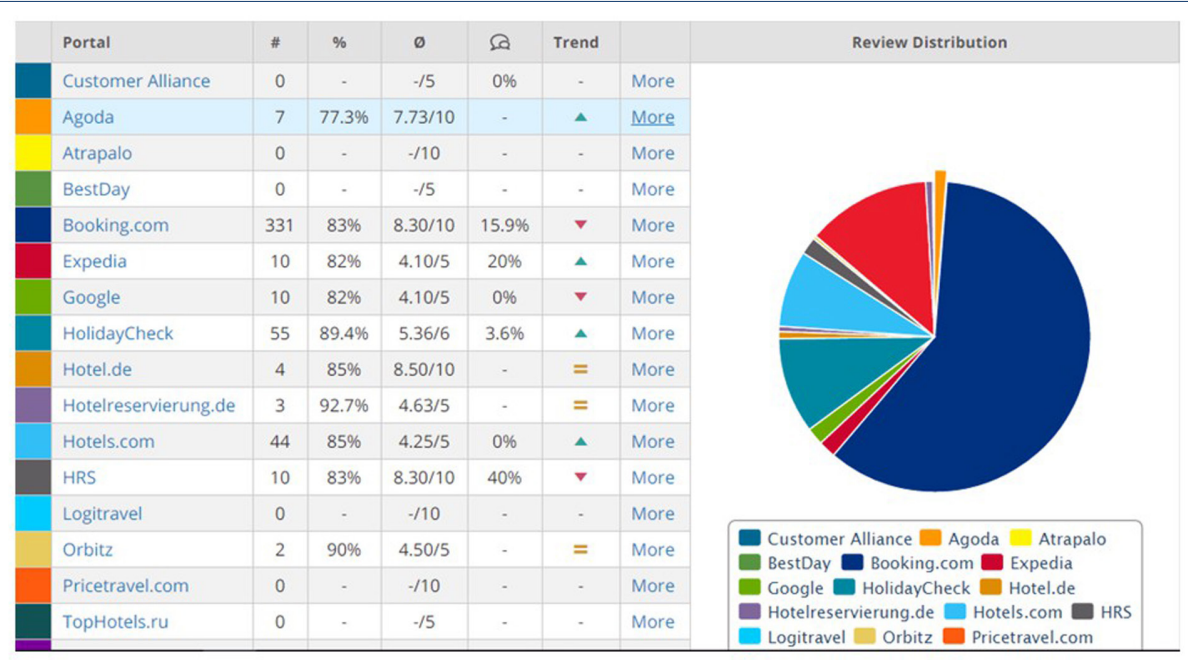

Figure 4. Customer Alliance Dashboard ${ }^{3}$

3 Snapshot from https://go.customer-alliance.com/, January 2016 

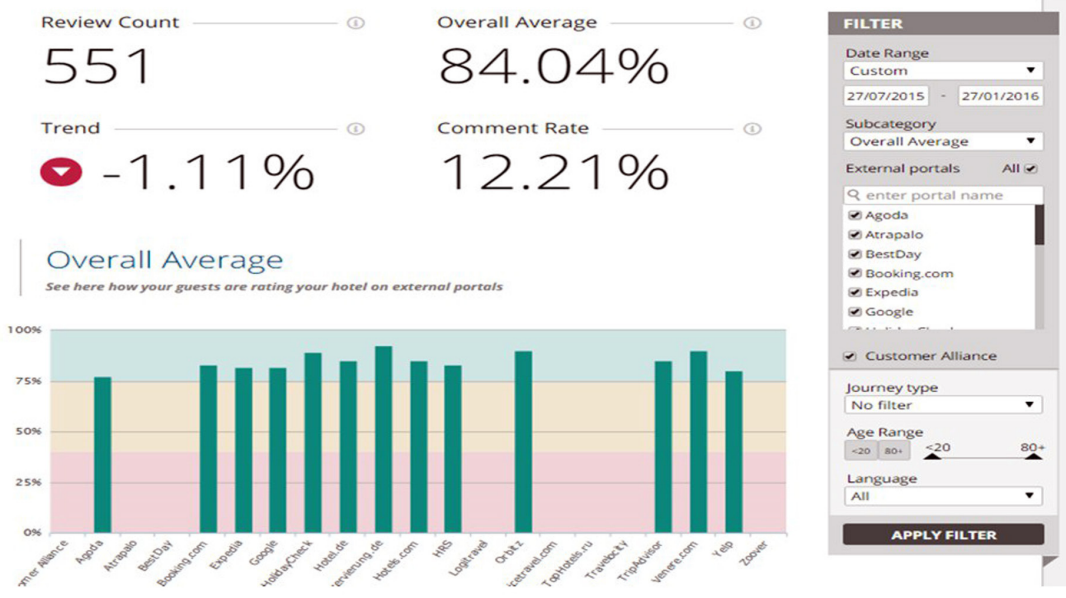

Figure 5. Customer Alliance Statistics ${ }^{4}$

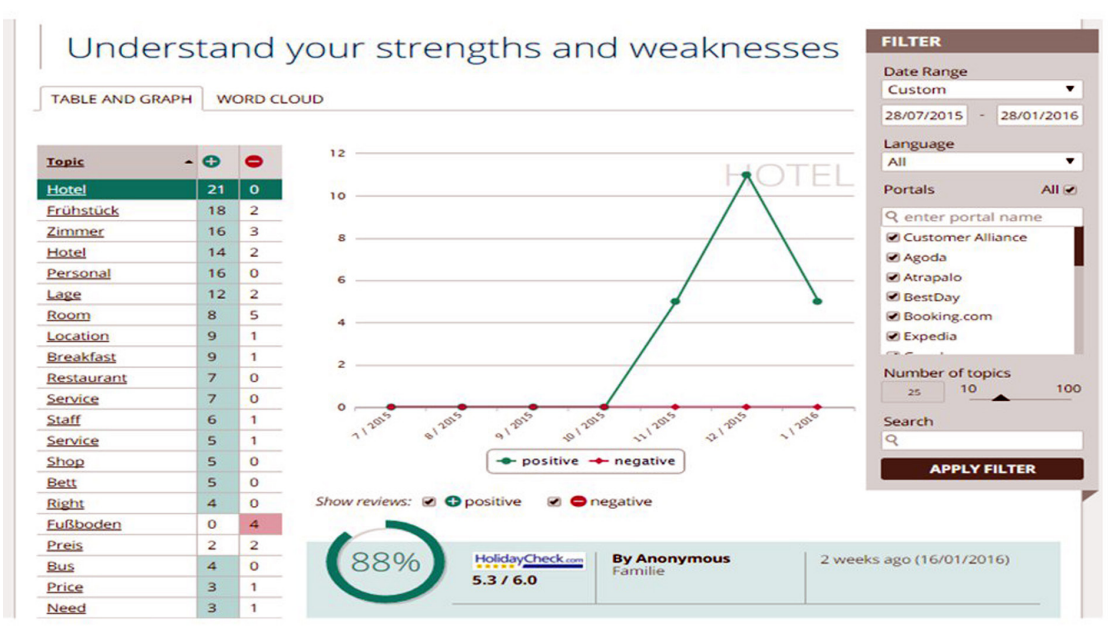

Figure 6. Customer Alliance Semantics ${ }^{5}$

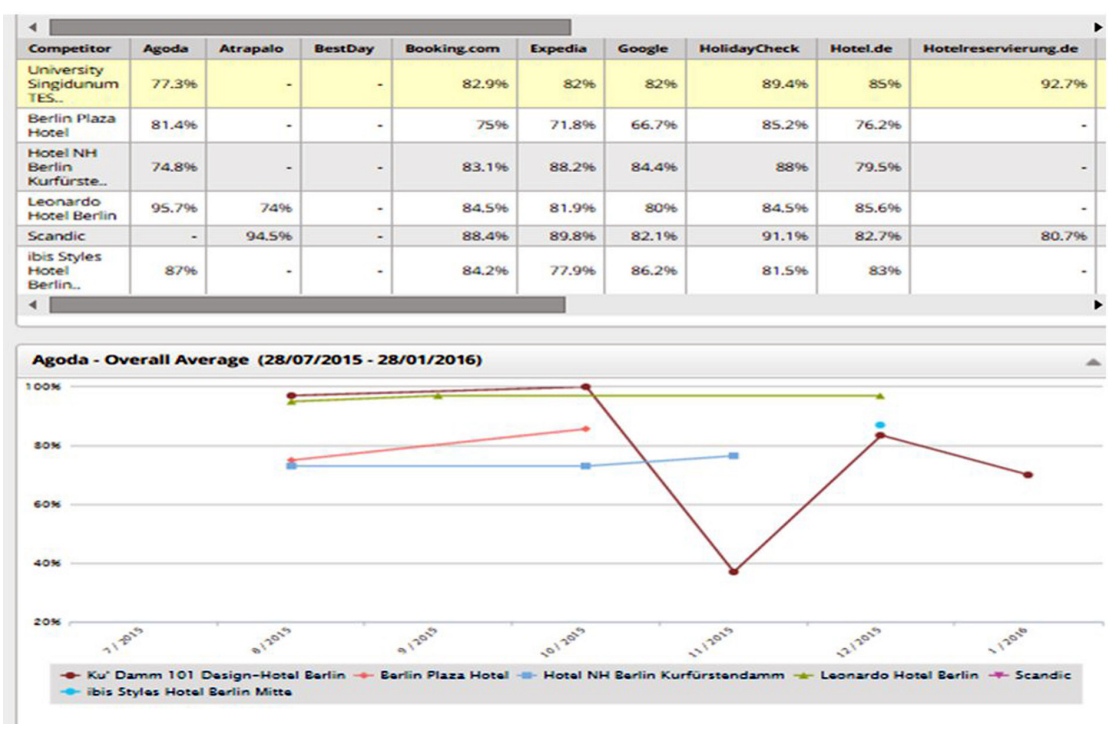

Figure 7. Customer Alliance Competition ${ }^{6}$

5 Snapshot from https://go.customer-alliance.om/, January 2016

6 Ibid. 